\title{
Nanocomposites: A mini review on their periodontal applications
}

\author{
Masood Bamedi \\ Department of Periodontology, Faculty of Dentistry and Oral and Dental Disease Research Center, Zahedan \\ University of Medical Science, Zahedan Iran
}

\begin{abstract}
Dental diseases routinely are being vastly increased in populations and there is a very effective need of finding novel therapeutic approaches. One of newest ways is the use of nanoparticles based applications. Recently, Nanoparticles are playing an important role in nanomedical applications particularly in dentistry specifically periodontology. Nanocomposites are a class of nanoparticle based materials which are widely used in dentistry, are also used in dental research and practice as effective and novel tools to solve periodontal and dental problems. In this review a focus has been made on nanoparticle based agents and their applications in peridontology.
\end{abstract}

KEY WORDS: PRIODONTOLOGY, NANOPARTICLE, NANOCOMPOSITES, NANOMEDICAL APPLICATIONS

\section{INTRODUCTION}

Periodontitis is a tainting including strong structures of the teeth which wins in all social affairs, ethnicities, races and both sexual presentation. It is multi-factorial in etiology, and microorganisms are one among these etiologic heads (Saravana et al., 2006 \&t Bumb et al., 2013). Along these lines, a key section of treatment depends upon to take out or control these pathogens and reestablish the periodontium to a typical helpful state. This has been generally refined through mechanical means, for example, scaling and root planning (SRP), open wrinkle debridement, and framework went for recovering the

\section{ARTICLE INFORMATION:}

"Corresponding Author:

Received $17^{\text {th }}$ March, 2017

Accepted after revision $19^{\text {th }}$ June, 2017

BBRC Print ISSN: 0974-6455

Online ISSN: 2321-4007 CODEN: USA BBRCBA

$\therefore$ Thomson Reuters ISI ESC and Crossref Indexed Journal

NAAS Journal Score 2017: 4.31 Cosmos IF : 4.006

- A Society of Science and Nature Publication, 2017. All rights reserved.

Online Contents Available at: http//www.bbrc.in/ periodontium and by the utilization of built specialists, for example, mouth washes and dentifrices. Systemic antimicrobials have been utilized as a partner close by such standard strategy. The utilization of such threatening to sullying authorities, yet serious, can't be totally maintained. This is in light of the way that, periodontal burden is site-particular in nature and subjecting the patient to obliging centralizations of unfriendly to pollution pros for brief eras powers rehashed dosing for longer periods (Virupakshappa 2012).

To pound the restraints of routine treatment with systemic antimicrobials, furtively passed on, opposing to infective pharmacological heads, most beginning late 
utilizing sustained release vehicles, have been shown. These covertly passed on antimicrobials are framed with the concerned arrangement impregnated in a vehicle and open as strands, chips, gels, emollients and microspheres. The approach of nanotechnology has updated the course in which these pharmaceutical transport structures have been made and passed on. In 2000, a research reverberated the 1959 gauge in the remarkable address by the late physicist Richard P Feynman. This longing kept running with the introduction of nanotechnology's definition and vision: that the nuclear level accuracy supervised by atomic gadgets working at the nanoscale was a sure technologic assurance (Freitas et al., 2000 Nikalje A.P. 2015).

Nanotechnology which is by and large called subatomic arranging is the time of realistic materials and structures in the degree of 0.1 to 100 nanometers by different physical and mix frameworks. Beginning late, the dynamic change of nanotechnology has changed into the most astoundingly braced get ready in science and technology. Polymers or microparticle-based hydrogels have been related in dentistry and periodontics particularly beginning at starting late, which can affect the rate of discharge in context of their structure, thusly the progress of more refined procedures for passing on drugs at therapeutic levels to particular objectives is an essential clinical issue, (Upadhyay et al., 2013 \&t Rao et al., 2013 Baheti et al., 2014 Wang et al., 2015).

\section{NANOPARTICLE BASED TECHNOLOGY}

Nanocomposite hydrogels are blended as model structures for in situ cured neighboring remedy development gadgets for the treatment of periodontal contaminations. The composite join the running with parts: nanoparticles, a system gel and the fitting antibacterial solution. The nanoparticles were picked up by free radical started copolymerization of monomers, 2hydroxy methymethacrylate (HEMA) and polyethyleneglycoldimethacrylate in watery strategy, (Wang et al., 2015 \& Sivaramakrishnanet al, 2014 \&t Hatziantoniou et al., 2006). Relative monomers were utilized to plan crosslinked lattices by photopolymerization. Nanocomposite hydrogels were gotten by blending nanoparticles, monomers and the medication in watery arrangement then cross related by photopolymerization. These nanoparticles are appropriate for mix into a hydrogel framework and to orchestrate new arrangement transport gadgets for dental and periodontal application. Endeavors to update the clinical execution of composite filling material depend on the running with maintopics: Reduction of the polymerization shrinkage.

\section{NANOCOMPOSITES AND DENTAL APPLICATIONS}

Nanocomposites have a filler stacking upto 95\% that help reduce polymerization shrinkage, - Improvement of the mechanical properties, especially wear resistance, - Improvement of bio compatibility by decreasing the elution of components Nanofiller particles may be of two types - Nanometric, particles (NM) - are monodisperse non add up to and non agglomerated silica particles which are treated with 3 methacryloxypropyltrimethoxysilane, (MPTS - coupling administrator) to keep any agglomeration or aggregation and allow chemical bonding of the NM filler of the gum, cross section in the midst of curing. (Fakruddin et al., 2012 \& DA Terry 2004). • Nanocluster (NC's) Particles have a fundamental atom size of 2 to $20 \mathrm{~nm}$, while the spheroid agglomerated particles have a broadsize distribution, with an average size of 0.6 micrometers. Nanoparticles with a balanced refractive record and radiopacity were gained by mixing mixed oxides, for instance, silica Zirconia nanoparticles (Kong et al., 2000, Nikalje, 2015).

Furthermore, all around arranged nano and microstructures sol gel can be utilized for conveying protective and wear safe coatings of teeth, metalalloys, and glass fillers of exceptional structures. As showed by late revelations, paying little personality to the finishing and cleaning procedure, the nanofilled composites showed the most diminished pretesting surface disagreeableness and wear starting late, the remarkable progress in treatment modalities have been found in the field of orthodontics, the self-ligating areas, changed treatment techniques, and Invisalign, to name the few. In spite of the way that the headway of orthodontic materials in the past 5 decades has been an astounding development twist depicted by times of unprecedented development with various upgrades took after by long peaceful intervals a representation being the destructive scratching framework, which was exhibited in the mid-1950s and ended up being all around recognized in the 1960s (Torres L et al., 2011 \& Breschi et al., 2010).

It assumed control 10 years for this practice to twist up unmistakably standard strategy in orthodontics on a broad scale. Nanoparticles have starting late channelized their way in Orthodontics in various modalities like bracketless tooth repositioning, nanocoated orthodontic wires to lessening granulating and besides by alveolar tissue development .Nanorobots tend to have high positional precision by navigational framework. After the fulfillment of their pined for exercises, they are assessed to be removed from the human body by human excretory channels (Almahdy et al., 2012 \& Sabatini et al., 2013 \&t Osorio et al., 2011 \&t Toledano et al., 2012).

Orthodontic nanorobots could clearly control the periodontal tissues, including gingival, periodontal ligament, cementum and alveolar bone, allowing quick and simple tooth correcting, turning and vertical reposi- 
tioning inside minutes to hours.10 It is seen that nanofilled composites has better fringe seal in complete and dentin commensurate to total destructive etching concretes and subsequently help in redesigned holding of areas to tooth structure 25. Sliding a tooth along an archwire incorporates a frictional sort of drive that contradict their advancement. Use of extravagant orthodontic compel may achieve loss of dock and root desorption. In a survey circulated by Katz, an abatement in granulating has been represented by covering the orthodontic wires with inorganic fullerenes-like tungsten disulfide nanoparticles (IF-WS2) which are known for their astounding oil properties therefore updating the sufficiency of sliding mechanics (Thompson et al., 2012 Et De Moraes Porto et al., 2012 \&t Dundar et al., 2011 Ouyang et al., 2011).

The contemporary dental expert has to his exchange, a wide grouping of materials to restore the lost casing and limit of spoiled teeth. Routine dental amalgam was, some time recently, for the most part used as the supportive material of choice in stress bearing zones as a result of its dominating quality, however waited behind to the extent feel on account of its unmistakable metallic shading. Mercury toxic quality issues were in like manner a stress with silver amalgam. Jazzy solicitations, especially in the front areas of the oral gap, required the use of tooth tinted materials for remedial purposes. Consequently, dental composites were introduced, which best in class from the fundamental unfilled gums to filled pitches and further to scaled down scale filled and mutt composite gums. In spite of the way that these composites were viably used as elegant helpful materials in the front district, they couldn't capably bear the commonsense stacking in the back ranges. In like manner, the characteristic polymerization shrinkage of these materials had a tendency to make stresses in both the composite recovery and in the including tooth structure. Poor fringe modification and shameful proximal contacts also added to composite dissatisfactions in back teeth. Conventional composite Class I and Class II modifying endeavors (Abou Neel et al., 2014 \&t Davies 2003 \&t Bressan et al., 2013 \&t Weber et al., 1992), were along these lines habitually associated with issues, for instance, postoperative misery, tooth break and opening of the supportive edges inciting to littler scale spillage and dreary caries. Since there exists an innate irregularity between the particle size of the normally unmistakable composite restorative material (40nm-0.7nm).

Bressan et al., (2013) and the nanoscopic tooth structure $(1 \mathrm{~nm}-10 \mathrm{~nm})$ including hydroxyapatite valuable stones, dentinal tubule and finish shafts, the connection between the standard composite tar and tooth structure tends to be inadmissible. Among the customary varieties of composite saps, mutt composites have more vital quality inferable from the more broad size dispersal of the filler particles when stood out from the unfilled and microfilled tars. Recent advances in the material sciences and nanotechnology has however incited to the change of pervasive nanocomposite materials. These are balanced composite saps in which the central common structure has been braced with nanofillers. The usage of nanocomposite tars considers an unrivaled nanoholding interface between the tooth structure and the accommodating material achieving an all the more consistent and regular interface.

Nanocomposites have a considerably greater volume of the nanomeric filler particles in the tar system, realizing upgraded physical, creation and normal properties. At the point when diverged from standard composites, nanocomposites have a more noticeable adaptable modulus and higher flexural, pliant and influence qualities, close by improved scratched region resistance. More conspicuous filler stacking moreover in this way diminishes the volume of the polymer system and toughens the composite pitch by extending hardness and break resistance and by lessening the thickness. The tension is passed on more reliably inside the gum. In like manner, the curing shrinkage abatements to half consequently does the shrinkage push. This is probably in light of the more grounded interfacial relationship of the regular sap cross section and the inorganic nanofiller particles, (Albrektsson et al., 2000).

The surface is smoother, with a higher translucency and clean support nearby better shade depiction. The nanoparticle size is more diminutive than the wavelength of clear light thusly the ingestion of light does not occur and light transmits through it. This assistants in keeping up the smoothness of the surface for a more drawn out period of time. More noticeable scattering of light by little evaluated nanoparticles in like manner conveys astonishing blending of the recovery, giving it a presence like effect. Basically smoother surfaces reduce the plaque gathering and resultant periodontal disease (Torres et al., 2011 \&t Thompson et al., 2012).

\section{RESULTS OF LITERATURE ANALYSIS}

Based on scientific analysis of more than 300 original research articles published during 2000-2015 covered by PubMed as well as Scopus databases with keywords of periodontal disease and Nanocomposites it was analyzed that it's a big demand on the use of such nanomaterials applications in 2006 since now.

In figure 1 it is illustrated that during years 20002005 there has been little applications of nanomedicine in periodontology, but after 2006 such nanomaterials have been widely used. 


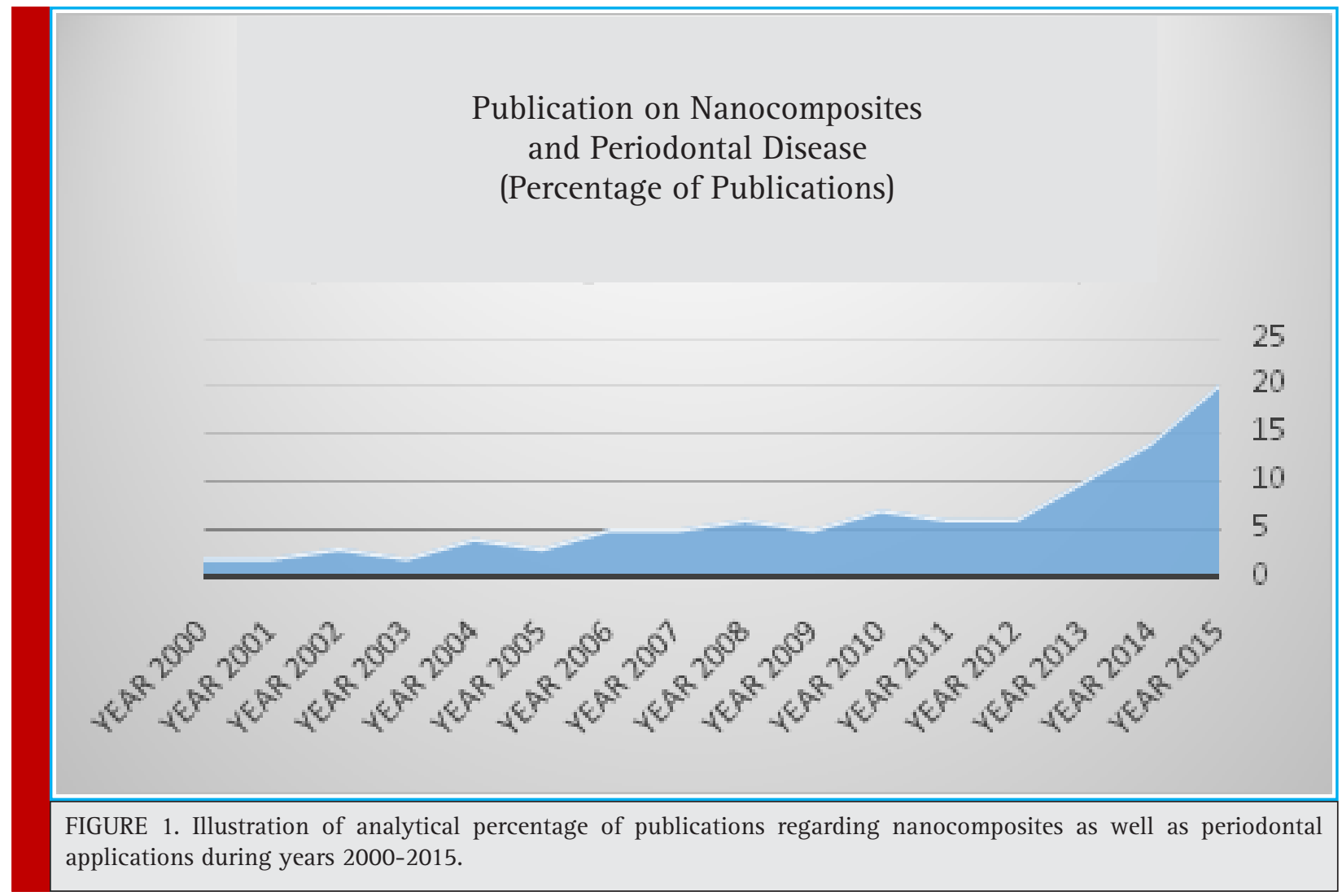

\section{REFERENCES}

Abou Neel EA, Chrzanowski C, Young AM.2000 Biointerfaces - Where Materials Meet Biology: Interfaces in Composite Materials. London: Royal Society of Chemistry; 2014.

Albrektsson T, Sennerby L, Wennerberg A. State of the art of oral implants. Periodontol2008;47:15-26.

Almahdy A, Koller G, Sauro S, et al. 2012 Effects of MMP inhibitors incorporated within dental adhesives. J Dent Res. 91(6):605-611.

Baheti M.J., ToshniwalN.G.2014 Nanotechnology: a boon to dentistry. J Dent Sci Oral Rehabil. 5:78-88.

Bresan E, Sbricoli L, Guazzo R, et al. 2013 Nanostructured surfaces of dental implants. Int J Mol Sci. 14:1918-1931

Breschi L, Martin P, Mazzoni A, et al. 2010 Use of a specific MMP-inhibitor (galardin) for preservation of hybrid layer. Dent Mater. 26(6):571-578.

Bumb S.S., Bhaskar D.J., Punia H.2013 Nanorobots and challenges faced by nanodentistry. Guident. 67-69.

DA Terry J. 2004 Direct applications of a nanocomposite resin system: Part 1 - The evolution of contemporary composite materials. PractProcedAesthet Dent. 16:417-422.

Davies JE. 2003 Understanding peri-implant endosseous healing. J Dent Educ. 67(8):932-949.

De Moraes Porto IC, De Andrade AK, Alves LC, Braz R. 2012 Effect of dentin pretreatment with potassium oxalate: analy- sis of microtensile bond strengths and morphologic aspects. Microsc Res Tech. 75(2):239-244

Dundar M, Ozcan M, Comlekoglu ME, Sen BH. 2011 Nanoleakage inhibition within hybrid layer using new protective chemicals and their effect on adhesion. J Dent Res. 90(1):93-98.

Fakruddin M., Hossain Z., Afroz H. 2012 Prospects and applications of nanobiotechnology: a medical perspective. J Nanobiotechnol. 10:1-8.

Freitas R.A. Nanodentistry. J Am Dent Assoc. 2000;131:15591565.

Hatziantoniou S., Demetzos C.2006 An introduction to nanotechnology in health care. Pharmakeftiki. 19(IV):86-88.

Hernandez J.D.L.F., Perez M.A.A., Valenzuela M.C.S. 2011 Use of new technologies in dentistry. Rev Odontol Mex. 15:158-163.

Kong L.X., Peng Z., Li S., Mark P.2000 Nanotechnology and its role in the management of periodontal diseases. Periodontology. 40:184-196.

Lainovic T., Vilotic M., Blazic L., Kakas D., Markovic D., Ivanisevic A.2013 Determination of surface roughness and topography of dental resin-based nanocomposites using AFM analysis. Bosn J Basic Med Sci. 13(1):35-43

Nikalje A.P. 2015 Nanotechnology - its applications in medicine. Med Chem. 5:81-89.

Osorio R, Yamauti M, Osorio E, et al.2011 Effect of dentin etching and chlorhexidine application on metalloproteinasemediated collagen degradation. Eur J Oral Sci.119(1):79-85. 
Ouyang X, Huang X, Pan Q, et al. 2011 Synthesis and characterization of triethylene glycol dimethacrylatenanocapsules used in a self-healing bonding resin. J Dent. 39(12):825-833.

Ozak S.T., Ozkan P. 2013 Nanotechnology and dentistry. Eur J Dent. 2013;7(1):145-151.

Rathee M., Bhoria M. 2014 Nanodentistry: the emerging tiny tools - a review. Int J BiosciNanosci. 1:63-67.

Rao K.V.P., Kumar J.S. Nanotechnology in dentistry. Kerala Dent J. 2013;36:56-59

Sabatini C. Effect of a chlorhexidine-containing adhesive on dentin bond strength stability. Oper Dent. 2013;38(6):609-617.

Saravana K.R., Vijaylakshmi R. Nanotechnology in dentistry. Indian J Dent Res. 2006;17:62-65.

Sauro S, Mannocci F, Toledano M, Osorio R, Pashley DH, Watson TF. 2009 EDTA or $\mathrm{H}_{3} \mathrm{PO}_{4} / \mathrm{NaOCl}$ dentine treatments may increase hybrid layers' resistance to degradation: a microtensile bond strength and confocal-micropermeability study. J Dent. 37(4):279-288.

Sivaramakrishnan S.M., Neelakanthan P. 2014 Nanotechnology in dentistry - what does the future hold in store. Dentistry. $4: 1-3$
Thompson JM, Agee K, Sidow SJ, et al.2012 Inhibition of endogenous dentin matrix metalloproteinases by ethylenediaminetetraacetic acid. J Endod. 38(1):62-65.

Toledano M, Yamauti M, Ruiz-Requena ME, Osorio R. 2012 A $\mathrm{ZnO}$-doped adhesive reduced collagen degradation favouring dentine remineralization. J Dent. 40(9):756-765.

Torres L.S., Marin L.M.L., Anita R.E.N., Padron G.H., Castano V.M.2011 Biocompatible metal-oxide nanoparticles: nanotechnology improvement of conventional prosthetic acrylic resins. J Nanomater:1-8.

Upadhyay Y. 2013 Current state and future perspectives of nanotechnology in dentistry. Int Organ Sci Res J Pharm. 3: 68-71.

Virupakshappa B. 2012 Applications of nanomedicine in oral cancer. Oral Health Dent Manag. 11:62-68.

Wang W., Liao S., Zhu Y., Liu M., Zhao Q., Fu Y. 2015 Recent applications of nanomaterials in prosthodontics. J Nanomateradvanced online publication

Weber HP, Fiorellini JP. 1992 The biology and morphology of the implant-tissue interface. Alpha Omegan. 85(4): 61-64 